\title{
Updated Korean Clinical Practice Guidelines on Decompressive Surgery for Malignant Middle Cerebral Artery Territory Infarction
}

\author{
Dae-Hyun Kim, ${ }^{a}$ Sang-Bae Ko, ${ }^{\mathrm{b}}$ Jae-Kwan Cha, ${ }^{\mathrm{a}}$ Keun-Sik Hong, ${ }^{\mathrm{c}}$ Kyung-Ho Yu, ${ }^{\mathrm{d}} \mathrm{Ji}$ Hoe Heo, \\ Sun-Uck Kwon, ${ }^{\mathrm{f}}$ Hee-Joon Bae, ${ }^{\mathrm{g}}$ Byung-Chul Lee, ${ }^{\mathrm{d}}$ Byung-Woo Yoon, ${ }^{\mathrm{b}}$ Jeong Eun Kim, ${ }^{\mathrm{h}}$

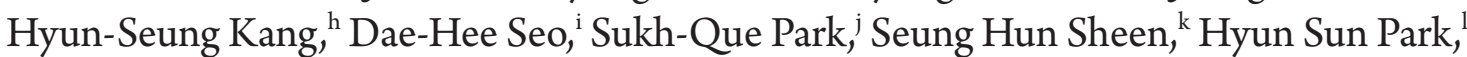 \\ Sung Don Kang, ${ }^{\mathrm{m}}$ Jae Min Kim, ${ }^{\mathrm{n}}$ Chang Wan Oh, ${ }^{\circ}$ In Sung Park, ${ }^{\mathrm{p}}$ Joung-Ho Rha ${ }^{\mathrm{q}}$ \\ a Department of Neurology, Dong-A University College of Medicine, Busan, Korea \\ 'Department of Neurology, Seoul National University College of Medicine, Seoul, Korea \\ 'Department of Neurology, Inje University College of Medicine, Goyang, Korea \\ ${ }^{\mathrm{d}}$ Department of Neurology, Hallym University College of Medicine, Anyang, Korea \\ e Department of Neurology, Yonsei University College of Medicine, Seoul, Korea \\ ${ }^{\mathrm{f}}$ Department of Neurology, University of Ulsan College of Medicine, Seoul, Korea \\ 'Department of Neurology, Seoul National University College of Medicine, Seongnam, Korea \\ ${ }^{\mathrm{h}}$ Department of Neurosurgery, Seoul National University College of Medicine, Seoul, Korea \\ iDepartment of Neurosurgery, Good Morning Hospital, Pyeongtaek, Korea \\ 'Department of Neurosurgery, Soonchunhyang University School of Medicine, Seoul, Korea \\ ${ }^{k}$ Department of Neurosurgery, Bundang Jesaeng General Hospital, Seongnam, Korea \\ ${ }^{1}$ Department of Neurosurgery, Inha University College of Medicine, Incheon, Korea \\ ${ }^{m}$ Department of Neurosurgery, Wonkwang University School of Medicine, Iksan, Korea \\ ${ }^{\mathrm{n}}$ Department of Neurosurgery, Hanyang University College of Medicine, Seoul, Korea \\ ${ }^{\circ}$ Department of Neurosurgery, Seoul National University College of Medicine, Seongnam, Korea \\ PDepartment of Neurosurgery, Gyeongsang National University School of Medicine, Jinju, Korea \\ ${ }^{q}$ Department of Neurosurgery, Inha University College of Medicine, Incheon, Korea
}

\section{Introduction}

Clinical practice guidelines (CPGs), which provide systemic reviews of accumulated scientific evidence, are used by clinicians to choose optimal treatment modalities. In Korea, the Clinical Research Center for Stroke (CRCS) published the first version of its CPGs for stroke in October 2009; it was based on articles that had been reported before June 2007. Since then, major trials of decompressive surgery for malignant middle cerebral artery (MCA) have been published, and the CRCS and Korean Society of Cerebrovascular Surgeons (KSCVS) therefore decided to revise the CPGs to reflect this new evidence.

To select source papers for the revision, we searched Pubmed for English-language articles published between July 2007 and May 2014 that contained the word "stroke," plus any one of the following terms or phrases: "malignant MCA infarction," "hemicraniectomy," and "decompressive surgery." We retrieved 122 articles with the key words "stroke" and "malignant MCA infarction," 136 articles with "stroke" and "hemicraniectomy," and 225 articles with "stroke" and "decompressive surgery."
Correspondence: Joung-Ho Rha Department of Neurology, Inha University Medical College, 27 Inhang-ro, Jung-gu, Incheon 22332, Korea

Tel: +82-32-890-3668

Fax: +82-32-890-3864

Email:jhrha@inha.ac.kr

Received: January 13, 2015

Revised: March 16, 2015

Accepted: April 2, 2015

This study was supported by a grant of the Korea Healthcare Technology R\&D Project (HI10C2020), Ministry of Health and Welfare, Republic of Korea. 
We then narrowed this pool of articles down by limiting the search to prospective, randomized clinical trials, pooled analyses, and meta-analyses and found five such articles that were published during this period.

We reviewed a total of five randomized, clinical trials, ${ }^{2-6}$ one pooled analysis, ${ }^{7}$ and one meta-analysis, ${ }^{4}$ including three studies $^{2,3,7}$ that were mentioned in the first edition.

The revised versions of the CPGs for decompressive surgery from the European Stroke Organization (ESO) (May 2008), ${ }^{8}$ the Scottish Intercollegiate Guidelines Network (December 2008) ${ }^{9}$, the National Clinical Guidelines for Stroke of the Royal College of Physicians ( July 2008) ${ }^{10}$, and the American Heart Association (AHA)/American Stroke Association (ASA) guidelines (published, respectively, in 2013 and 2014) $)^{11,12}$ were also considered.

After we reviewed these articles and described new evidence in guidelines, each piece of evidence and recommendation was given a strength based on a definition of evidence level and recommendation grade used in the KSCVS and the CRCS guidelines (Table 1).

Our purpose in updating the CPGs is to incorporate the new evidence and to help physicians, patients with malignant MCA infarction, and their caregivers make decision regarding decompressive hemicraniectomy. The recommendations were peer reviewed by steering committee members of the CRCS. A consensus meeting convening experts from the Korean Stroke Society and the KSCVS was also held on January ${ }^{13}, 2014$, to determine the level of evidence and grade of recommendation.

\section{Previous recommendations for decompressive surgery}

The first version of the CPGs recommended decompressive surgery for malignant MCA infarction to reduce mortality and improve neurological outcome. This recommendation was gen- erated from reviews of the European Stroke Initiative clinical practice guidelines, ${ }^{13}$ the $2007 \mathrm{AHA} / \mathrm{ASA}$ guidelines for the early management of stroke, ${ }^{14}$ and two clinical trials ${ }^{2,3}$ and metaanalyses, ${ }^{7}$ all published before June 2007. However, the earlier recommendations did not specifically state the timing of surgery or the age of the patients.

\section{Previous recommendation of the Korean CPGs for Stroke, version 1}

With decompressive surgery for the relief of malignant edema due to cerebral infarction, the patient's life can be saved and neurological improvement can be expected. Patient age and the location of infarction (i.e., nondominant or dominant hemisphere) may be factors that determine whether surgery should be performed. It is recommended that patients with severe edema undergo surgery. It is necessary, however, for the clinicians to determine whether the patient might be left with severe disability for life (level of evidence IIa, grade of recommendation B).

\section{New evidence from clinical trials and meta-analyses}

Sequential-Design, Multicenter, Randomized,
Controlled Trial of Early Decompressive Craniectomy
in Malignant Middle Cerebral Artery Infarction
(DECIMAL Trial)
DECIMAL ${ }^{2}$ was a multicenter randomized clinical trial conducted in France, compared decompressive surgery and medical management in patients with malignant MCA infarction. Decompressive surgery was performed within 36 hours of symptom onset. The inclusion criteria for malignant MCA infarction were (1) National Institutes of Health Stroke Scale (NIHSS) score of 16 points or more, (2) 1 more points on the NIHSS mental deterioration inventory, and (3) computed tomography $(\mathrm{CT})$ find-

Table 1. Evidence levels and recommendation grades used by the Korean Society of Cerebrovascular Surgeons and the Clinical Research Center for Stroke

\begin{tabular}{|c|c|}
\hline Level of evidence & \\
\hline la & Meta-analysis of randomized controlled trials \\
\hline $\mathrm{lb}$ & At least one randomized controlled trial \\
\hline Ila & At least one well-designed controlled study without randomization \\
\hline$\| \mathrm{lb}$ & At least one other type of well-designed quasi-experimental study \\
\hline III & Well-designed nonexperimental descriptive studies (e.g., comparative studies, correlation studies and case studies) \\
\hline IV & Expert committee reports or opinions and/or clinical experiences of respected authorities \\
\hline Grade of recomme & \\
\hline $\mathrm{A}(\mathrm{LOE} \mathrm{la}, \mathrm{lb})$ & At least one randomized controlled trial as part of the body of literature of overall good quality and consistency addressing specific recommendation \\
\hline $\mathrm{B}(\mathrm{LOE} \| \mathrm{la}, \mathrm{llb}, \mathrm{II})$ & Availability of well-conducted clinical studies but no randomized clinical trials on the topic of recommendation \\
\hline C(LOE IV) & $\begin{array}{l}\text { Expert committee reports or opinions and/or clinical experiences of respected authorities; indicates absence of directly } \\
\text { applicable clinical studies of good quality }\end{array}$ \\
\hline
\end{tabular}


ings suggestive of cerebral infarction in more than $50 \%$ of the MCA regions or a volume of cerebral infarction exceeding 145 $\mathrm{cm}^{3}$ on diffusion-weighted brain magnetic resonance imaging (DWI).

Total infarction volume on DWI can be measured in a semiautomatic manner in malignant MCA infarction. It is calculated by adding all areas of abnormal hyperintense signal on each section, then multiplying by the slice thickness plus the intersection gap. ${ }^{15}$

The primary endpoint was good outcome, defined as a modified Rankin Scale (mRS) score of 0 to 3 at 6 months. The trial was terminated early by the safety monitoring committee, after 38 patients had been enrolled, because of slow enrollment and plans for a pooled analysis with similar trials. The proportion of patients with $\mathrm{mRS}$ scores of 0 to 3 at 6 months was higher in the decompressive surgery group than in the medical management group, but the difference was not statistically significant $(25.0 \%$ vs. $5.6 \% ; P=0.18$ ). However, mortality was significantly reduced with decompressive surgery compared with that with medical management ( $25 \%$ vs. $77.8 \% ; P<0.0001)$, and the difference in mortality was maintained at 1 year. In conclusion, DECIMAL demonstrated that decompressive surgery was effective in reducing mortality by more than $50 \%$ compared with medical management in patients with malignant MCA infarction.

\section{Decompressive Surgery for the Treatment of Malignant Infarction of the Middle Cerebral Artery (DESTINY)}

DESTINY, ${ }^{3}$ a prospective multicenter randomized trial conducted in Germany, compared decompressive surgery performed within 36 hours of symptom onset and conservative therapy in patients with malignant MCA infarction ages 18 to 60 years. The trial was designed as a sequential trial to assess 30-day mortality as the first efficacy endpoint and to sequentially determine the sample size needed to demonstrate the effect of decompressive surgery with the 6-month $\mathrm{mRS}$ score of 0 to 3 as a primary endpoint.

Inclusion criteria for malignant MCA infarction were (1) clinical presentation of MCA infarction with an NIHSS scores greater than 18 for nondominant hemisphere or an NIHSS score greater than 20 for dominant hemisphere, (2) decrease in level of consciousness as defined by a score of 1 or greater on item la of the NIHSS, and (3) CT-documented unilateral MCA infarction, including more than two thirds of the territory and including at least part of the basal ganglia.

After 32 patients were enrolled, the comparison for the first efficacy endpoint of 30-day mortality met statistical significance for the superiority of decompressive surgery over conservative therapy $(12 \%$ vs. $53 \%$; $P=0.02)$. Rather than continuous enroll- ment to determine the effect of surgery on functional disability, the steering committee decided to stop the trial and instead perform a pooled analysis with similar trials. The difference in mortality remained significant at 6 and 12 months ( $18 \%$ vs. 53\%; $P=0.03$ ). The proportion of mRS score of 0 to 3 at 6 months, which was considered the primary endpoint for the planned target sample size, was higher in the surgery group than in the conservative treatment group, but the difference was not statistically significant ( $47 \%$ vs. $27 \%$; $P=0.23$ ). However, the $\mathrm{mRS}$ distribution analysis showed a favorable shift toward better functional outcomes with decompressive surgery $(P=0.04)$. In conclusion, DESTINY demonstrated that decompressive surgery reduced mortality and resulted in a favorable shift in the mRS disability distribution.

\section{Early decompressive surgery in malignant infarction of the middle cerebral artery: a pooled analysis of three randomized controlled trials}

This pooled analysis ${ }^{7}$ included patients enrolled in the early terminated DECIMAL ${ }^{2}$ and DESTINY ${ }^{3}$ trials and in the ongoing Hemicraniectomy After Middle cerebral artery infarction with Life-threatening Edema Trial (HAMLET). ${ }^{4}$

The inclusion criteria for this pooled analysis were (1) age between 18 and 60 years, (2) surgery within 48 hours of onset of stroke, (3) NIHSS score higher than15, (4) decreased level of consciousness as defined by a score of 1 or higher on item 1a of the NIHSS, and (5) infarction of more than 50\% of the MCA territory on CT or infarction volume greater than $145 \mathrm{~cm}^{3}$ on DWI.

The primary endpoint was the proportion of patients with $\mathrm{mRS}$ scores of 0 to 4 at 1 year. A total of 93 patients ( 38 from DECIMAL, 32 from DESTINY, and 23 from HAMLET) were included in this pooled analysis. At 1 year, $75 \%$ of the surgery group and $24 \%$ of the control group had mRS scores of 0 to 4 (pooled absolute risk reduction $[\mathrm{ARR}], 51 \%$ [95\% confidence interval $\{\mathrm{CI}\}$, 34-69]; Number Needed to Treat $[\mathrm{NNT}]=2 ; P<0.0001$ for significance and $P=0.74$ for heterogeneity). In addition, decompressive surgery was associated with higher proportion of mRS 0 to 3 outcome ( $43 \%$ vs. $21 \%$; pooled ARR, $23 \%$ [95\% CI 5-41]; $\mathrm{NNT}=4 ; P=0.014$ for significance and $P=0.89$ for heterogeneity) and better survival (78\% vs. $29 \%$; pooled ARR, 50\% [95\% CI 33-67]; NNT $=2$; $P<0.0001$ for significance and $P=0.34$ for heterogeneity). In conclusion, this pooled analysis demonstrated that decompressive surgery within 48 hours of onset reduced mortality and increased survival, with a good functional outcome, in patients with malignant MCA infarction. 
Surgical decompression for space-occupying cerebral infarction (the Hemicraniectomy After Middle Cerebral Artery Infarction with Life-Threatening Edema Trial [HAMLET])

HAMLET, ${ }^{4}$ a prospective multi-center randomized trial conducted in the Netherlands, compared decompressive surgery within 96 hours of onset (longer than the intervals used in DECIMAL and DESTINY) and best medical treatment in patients ages 18 to 60 years with space-occupying hemispheric infarction.

The inclusion criteria for space-occupying hemispheric infarction were (1) MCA territory infarction with NIHSS score higher than 15 for right-sided lesions or higher than 20 for left-sided lesions, (2) gradual decrease in consciousness to a score of less than 14 on the Glasgow Coma Scale for right-sided lesions or an eye and motor score of less than 10 for left-sided lesions, and (3) ischemic changes on CT on two thirds of the MCA territory and the formation of space-occupying edema.

The primary endpoint was an $\mathrm{mRS}$ score of 0 to 3 at 1 year. Sixty-four patients were enrolled, and the median time between onset and randomization was 41 hours for the surgery group and 45 hours for the medical treatment group (39 patients were randomized within 48 hours). Decompressive surgery, compared with best medical treatment, did not increase the proportion of mRS score of 0 to 3 ( $25 \%$ vs. $25 \%$; $P>0.999$ ) but significantly reduced mortality (22\% vs. 59\%; ARR 38\% [95\% CI 15-60]; $P=0.002$ ). In subgroup analyses, patients randomized within 48 hours benefited from decompressive surgery for reducing $\mathrm{mRS}$ 5 to 6 outcome ( $48 \%$ vs. $78 \%$; ARR 30\% [95\% CI 1-59]) and mortality (19\% vs. 78\%; ARR 59\% [95\% CI 33-84]), whereas in those randomized after 48 hours, decompressive surgery did not significantly reduce mRS 5-6 outcome and mortality.

In an updated meta-analysis of 109 patients randomized within 48 hours in DECIMAL, DESTINY, and HAMLET, decompressive surgery reduced mortality at 1 year (ARR 49.9\% [95\% CI 33.9-65.9]; P for heterogeneity $=0.53)$ and extreme disability or death, defined as an mRS score of 5 to 6 (ARR 41.9\% [95\% CI 25.2-58.6]; P for heterogeneity $=0.52$ ), and the effect on reducing mRS outcome of 4 to 6 was statistically marginal (ARR $16.3 \%$ [95\% CI -0.1-33.1]; P for heterogeneity $=0.40)$.

In conclusion, decompressive surgery performed within 48 hours reduced mortality and extreme disability or death, but there was no benefit for surgery performed up to 96 hours after onset. However, clinical trials and meta-analyses of decompressive surgery in patients aged 60 and younger with malignant MCA infarction did not provide clear evidence of the effect of surgery on the quality of life.

\section{Decompressive Surgery for the Treatment of Malignant Infarction of the Middle Cerebral Artery II (DESTINY II)}

In contrast to the previous trials, which excluded patients older than 60 years, DESTINY5 examined the efficacy of decompressive surgery performed within 48 hours in patients older than 60 years. The other inclusion criteria were almost identical to those of the DESTINY trial, in which patients aged 18 to 60 years were enrolled. In accordance with the pooled analysis of DECIMAL, HAMLET, and DESTINY data, the primary endpoint was functional outcome on the $\mathrm{mRS}$ score, dichotomized into 0 to 4 vs. 5 or 6 at 6 months.

After 112 patients had been enrolled, the data and safety monitoring board recommended that further recruitment be stopped in light of the findings of interim analysis of the primary endpoint for the first 82 patients.

The proportion of patients who survived without severe disability (mRS 0-4) was 38\% in the hemicraniectomy group and $18 \%$ in the control group (odds ratio [OR] 2.91; 95\% CI 1.067.49; $P=0.04$ ). This difference was mainly driven by the lower mortality in the surgery group (33\% vs. $70 \%$ ). However, no patient in either group achieved an mRS score of 0 to 2 . The remaining disability proportions in the surgery and control groups, respectively, were $7 \%$ vs. $3 \%$ for mRS 3 outcome, $32 \%$ vs. $15 \%$ for mRS 4 outcome, and $28 \%$ vs. $13 \%$ for mRS 5 outcome. For the endpoints of activity of daily living, quality of life, and depression, the intention-to-treat analysis (including dead patients, for whom worst values were assigned), showed that all of the measures significantly favored surgery. However, in the analysis restricted to patients who survived, the differences in these measures were not significant between the two groups.

In conclusion, DESTINY II showed that decompressive surgery in patients older than 60 years is a lifesaving procedure and increases the chance of survival without complete dependency.

Even though the DESTINY II study proved that treatment is effective in patients 60 years and older, surgery in patients 80 years and older must be carefully considered, and further studies are needed.

\section{Hemicraniectomy and Durotomy on Deterioration} From Infarction-Related Swelling Trial (HeADDFIRST)

$\mathrm{HeADDFIRST}^{6}$ was a randomized pilot study intended to evaluate the benefit of surgical decompression for brain swelling due to large supratentorial cerebral hemispheric infarction.

The inclusion criteria for brain swelling from large supratentorial cerebral hemispheric infarction were (1) age 18 to 75 years, (2) NIHSS score of 18 or more and responsiveness to minor stimulation (NIHSS item $1 \mathrm{a}<2$ ), and (3) hypodensity involv- 
ing at least $50 \%$ of the MCA territory on CT performed less than 5 hours after the onset of stroke or hypodensity involving the entire MCA territory on CT less than 48 hours after stroke onset. Among patients who met criteria 1 through 3 , those with deterioration within 96 hours were classified as 1 or more (according to these criteria: [i] Horizontal anterior septum pellucidum shift from the midline of at least $7.5 \mathrm{~mm}$ with unchanged or worsened neurological findings; or [ii] at least $4 \mathrm{~mm}$ of horizontal pineal shift from the midline with depression of arousability to the level of effortful awakening with immediate subsequent sleepiness or worse [NIHSS item $1 \mathrm{a} \geq 2]$ ), and were randomized to continued medical treatment only or medical treatment plus surgery.

Twenty-five patients within 96 hours of stroke onset were randomized. Among these patients, the primary endpoint of mortality at 21 days was $21 \%$ in the surgical group and $40 \%$ in the standardized medical treatment group, but the reduction was not statistically significant because of the small sample size (ARR 19\% [95\% CI -13\%-50\%]). No data on functional outcome or timing of the surgical intervention were reported in this study. Fourteen patients who failed to meet the randomization criteria and who underwent standardized medical treatment were alive at 21 days.

The strict randomization criteria of the HeADDFIRST study could effectively distinguish low risk from high risk of death resulting from large supratentorial cerebral hemispheric infarction. Lower mortality in the medical treatment-only group than in other published trials suggests a benefit to standardizing medical management.

Table 2 summarizes the designs and results of the randomized controlled trials and their meta-analysis testing decompressive hemicraniectomy in patients with malignant MCA territory infarction.

\section{Surgical method for decompressive surgery for malignant MCA infarction}

In addition to randomized trials, clinical studies have been conducted to evaluate surgical methods in Korea and other countries. In general, decompressive surgery consists of large hemicraniectomy and duraplasty including the temporal lobe, frontal lobe, and parietal lobe areas. The minimal anterior-posterior diameter of the bone flap should be $12 \mathrm{~cm} \cdot{ }^{16,17}$ Special care should be taken not to damage the brain and blood vessels. With an incision of the dura mater and duraplasty involving the use of autologous periosteum or artificial dura matter, clinicians should ensure that the brain can be further relaxed. Clinicians who consider that it is difficult to decompress the brain solely with hemicraniectomy and duraplasty because of severe swelling may choose to resect the temporalis muscle. ${ }^{18}$ Although some retrospective studies have reported the decompressive effect of the temporal lobectomy, ${ }^{19,20}$ randomized prospective clinical trials regarding the benefit of additional lobectomy should be mandatory because of the lack of clinical evidence. Moreover, additional lobectomies were not conducted in the aforementioned prospective controlled randomized multicenter trials showing evidence supporting the use of decompressive surgery for malignant MCA infarction. ${ }^{2-7}$

Bone fragments can be preserved in a deep freezer or the patient's abdominal wall. To date the optimal temperature for bone flap storage has not been clarified, but a range of $-18^{\circ} \mathrm{C}$ to $-83^{\circ} \mathrm{C}$ has been described. ${ }^{21}$ Cranioplasty, once the cerebral edema has subsided, is recommended. Cranioplasty is recommended in a diverse range of times, from 6 weeks to 6 months. There is no clinical study regarding the effect of the timing of reinsertion on clinical outcome. According to the available per-

Table 2. Summary of randomized controlled trials and meta-analyses of decompressive surgery in patients with malignant middle cerebral artery infarction

\begin{tabular}{|c|c|c|c|c|c|c|c|c|c|}
\hline & \multirow{2}{*}{ Eligibility criteria } & \multirow{2}{*}{$\begin{array}{c}\text { Time window } \\
\text { (month) }\end{array}$} & \multirow{2}{*}{$\begin{array}{l}\text { No. of } \\
\text { patients }\end{array}$} & \multirow{2}{*}{$\begin{array}{l}\text { Age } \\
\text { (year) }\end{array}$} & \multirow{2}{*}{ Primary outcome } & \multicolumn{2}{|c|}{ Functional outcome (\%) } & \multicolumn{2}{|c|}{ 12-Month mortality (\%) } \\
\hline & & & & & & Surgical & Medical & Surgical & Medical \\
\hline DECIMAL $^{2}$ & $\begin{array}{l}\text { NIHSS }>15 \text { and NIHSS Item } 1 \mathrm{a}>0 \\
>1 / 2 \text { MCA territory or DWI }>145 \mathrm{~mL}\end{array}$ & 36 & 38 & $18-55$ & mRS $0-3$ vs. $4-6$ at 6 months & 25 & 6 & 25 & 78 \\
\hline DESTINY3 & $\begin{array}{l}\text { NIHSS }>18^{-} \text {or } 20^{+} \text {and NIHSS } \\
\text { Item1 } 1 \mathrm{a}>0,>2 / 3 \text { MCA territory }\end{array}$ & 36 & 32 & $18-60$ & mRS 0-3 vs. 4-6 at 6 months & 47 & 27 & 18 & 53 \\
\hline Pooled analysis $^{7}$ & & 48 & 93 & $18-60$ & mRS $0-4$ vs. $5-6$ at 12 months & 75 & 24 & 22 & 71 \\
\hline HAMLET $^{4}$ & $\begin{array}{l}\text { NIHSS }>15^{-} \text {or } 20,{ }^{+} \mathrm{GCS}<14^{-} \text {or } 10^{+} \\
>2 / 3 \text { MCA territory }\end{array}$ & 96 & 64 & $18-60$ & mRS $0-3$ vs. $4-6$ at 12 months & 25 & 25 & 22 & 60 \\
\hline Meta-analysis ${ }^{4}$ & & 48 & 109 & $18-60$ & mRS $0-4$ vs. $5-6$ at 12 months & 75 & 33 & 21 & 71 \\
\hline DESTINY $\|^{5}$ & $\begin{array}{l}\text { NIHSS } \geq 15^{-} \text {or } 20_{1}^{+} \\
>2 / 3 \mathrm{MCA} \text { territory }\end{array}$ & 48 & 112 & $\geq 60$ & mRS 0-4 vs. 5-6 at 6 months & 38 & 18 & 43 & 76 \\
\hline $\mathrm{HeADDFIRST}^{6}$ & $\begin{array}{l}\text { NIHSS }>17 \text {, NIHSS Item } 1 \mathrm{a}<2 \text {, } \\
>1 / 2 \text { MCA within } 5 \text { hours or complete } \\
\text { MCA within } 48 \text { hours }\end{array}$ & 96 & 24 & $18-75$ & mRS $0-5$ vs. 6 at 21 days & 79 & 60 & & \\
\hline
\end{tabular}

DECIMAL, the French DEcompresssive Craniectomy In MALignant middle cerebral artery infarcts; DESTINY, the German DEcompressive Surgery for the Treatment of malignant INfarction of the middle cerebral artery trial; HAMLET, the Dutch Hemicraniectomy after Middle cerebral Artery infarction with Life-threatening Edema Trial; HeADDFIRST, Hemicraniectomy And Durotomy upon Deterioration From Infarction Related Swelling Trial; NIHSS, National Institute for Health Stroke Scale; MCA, middle cerebral artery; DWI, diffusion-weighted image; mRS, modified Rankin scale; GCS, Glasgow coma scale; -/+, non-dominant/dominant hemisphere. 
tinent literature, timing itself is not related to complications, but early reinsertion, before 3 months of storage has elapsed, is generally recommended because of the risk of infection. ${ }^{22-27}$ Headache, seizures, and local neurological deficits are possible because of sinking skin flap syndrome after the cerebral edema subsides. It is therefore desirable not to delay cranioplasty too long. ${ }^{28,29}$ Biocompatible porous polyethylene implants or customized cranioplasty with polymethyl-methacrylate implants made with the use of a three-dimensional printer may be useful in the reconstruction of various cranial defects. ${ }^{30}$

\section{Current status of revisions in other guidelines}

In 2003, the European Union Stroke Initiative (EUSI) stated that decompressive surgery might be performed for life-saving purpose in patients with malignant MCA infarction. ${ }^{13}$ In the revised version, dated May 2008, decompressive surgery is recommended in patients 60 years and younger within 48 hours of onset. ${ }^{8}$ Compared with the level of evidence III published in 2003, the revised version published in 2008 was upgraded to the level of class I evidence and the level of recommendation of $\mathrm{A}$ on the basis of a pooled analysis of the HAMLET, ${ }^{7}$ DECIMAL $^{2}$ and DESTINY $^{3}$ trials conducted in 2007.

Decompressive surgery within 48 hours of onset is also recommended (grade of recommendation A) in the revised version of the Scottish Intercollegiate Guidelines Network, published in December 2008, for patients with malignant MCA infarction ages 60 years and younger. ${ }^{9}$

In July 2008, the National Clinical Guidelines for Stroke, from the Royal College of Physicians, also recommended decompressive surgery within 48 hours of onset for the following patients: (1) those 60 years or younger, (2) those with clinical deficits suggestive of infarction in the MCA territory, (3) those with NIHSS scores higher than 15 points, (4) those with decreases in level of consciousness to a score of 1 or higher on the NIHSS Item 1a, and (5) those with signs on CT of an infarct affecting more than $50 \%$ of the MCA territory with or without additional infarction in the territory of the anterior or posterior cerebral artery on the same side, or an infarction volume greater than 145 $\mathrm{cm}^{3}$ on DWI. ${ }^{10}$

In addition, the updated guidelines of the AHA/ASA, published in 2013 and 2014, ${ }^{11,12}$ recommend that decompressive craniectomy with dural expansion be strongly considered in patients younger than 60 years with malignant MCA infarction who deteriorate neurologically within 48 hours despite medical therapy (class I, level of evidence B). Although the optimal trigger for decompressive craniectomy is unknown, it is reasonable to use a decrease in level of consciousness, attributable to brain swelling, as the selection criterion (class IIa, level of evidence A). The efficacy of decompressive craniectomy in patients older than 60 years and the optimal timing of surgery are uncertain (class IIb, level of evidence C).

\section{Revised Recommendation of the Korean Clinical Practice Guidelines for Stroke}

On the basis of the results of five randomized clinical trials, one pooled analysis, and one metaanalysis, it can be concluded that decompressive surgery undertaken within 48 hours reduces mortality in patients with malignant MCA infarction who are 60 years or younger and in those who are older than 60 (Table 3 ). In addition, decompressive surgery increases the probability of survival with moderate or severe disability (mRS 0-4) in patients ages 60 or younger and survival with severe disability in patients older than 60 . Accordingly, we have updated the recommendations regarding the level of evidence and the grade of recommendation, age as a factor, and timing of surgery. In contrast to the previous recommendations, we provide specific criteria for malignant MCA infarction to help physicians select surgery candidates:

1) Decompressive hemicraniectomy within 48 hours after stroke onset is recommended in patients with malignant MCA infarction who are 60 years or younger (level of evidence Ia, grade of recommendation $\mathrm{A}$ ) or older than 60 years (level of evidence $\mathrm{Ib}$, grade of recommendation $\mathrm{A}$ ) and meet all of the fol-

Table 3. The 2015 update of the Korean Clinical Practice Guideline for stroke recommendations for decompressive craniectomy in patients with malignant MCA infarction

Revised Recommendation of the Korean Clinical Practice Guidelines for Stroke

1. Decompressive hemicraniectomy within 48 hours of stroke onset is recommended in patients with malignant MCA infarction who are 60 years or younger (level of evidence la, grade of recommendation $\mathrm{A}$ ) or older than 60 years (level of evidence $\mathrm{lb}$, grade of recommendation $\mathrm{A}$ ) and meet all of the following criteria:

(1) clinical symptoms and signs of infarction in the MCA territory,

(2) NIHSS score of 16 points or more,

(3) decrease in level of consciousness as defined by an NIHSS item 1a score of 1 point or more, and

(4) infarction affecting more than $50 \%$ of the total MCA territory on CT or an infarct volume greater than $145 \mathrm{~cm}^{3}$ on diffusion-weighted MRI.

2. The physician should inform the patient's family or guardian(s) of the potential outcome of survival with severe disability and lack of evidence of the benefit of surgery on the quality of life (grade of recommendation GPP). 
lowing criteria: (1) clinical symptoms and signs of infarction in the MCA territory, (2) NIHSS score of 16 points or more, (3) decrease in the level of consciousness (defined as an NIHSS item 1a score of at least 1 point), and (4) infarction of more than $50 \%$ of the total MCA territory on CT or an infarct volume greater than $145 \mathrm{~cm}^{3}$ on DWI.

2) The physician should inform the patient's family or guardian(s) of the potential outcome of survival with severe disability and the lack of evidence for the benefit of surgery on the quality of life (grade of recommendation GPP).

Despite the effect of decompressive hemicraniectomy on reducing mortality and severe disability, there is no clear evidence that the surgery improves quality of life in survivors. Further investigation of this aspect is needed.

\section{Conflicts of interest}

The Korea Healthcare Technology R\&D Project, which funded our study, was not involved in the preparation and publication of these current guidelines. The writing members of these guidelines were not influenced by their interest in any organization or affiliated institution.

\section{References}

1. The writing group of clinical practice guideline for stroke. Clinical Practice Guideline for Stroke. 1st ed. Seoul: Clinical Research Center for Stroke, 2009.

2. Vahedi K, Vicaut E, Mateo J, Kurtz A, Orabi M, Guichard JP, et al. Sequential-design, multicenter, randomized, controlled trial of early decompressive craniectomy in malignant middle cerebral artery infarction (DECIMAL trial). Stroke 2007;38: 2506-2517.

3. Juttler E, Schwab S, Schmiedek P, Unterberg A, Hennerici M, Woitzik J, et al. Decompressive surgery for the treatment of malignant infarction of the middle cerebral artery (DESTINY): a randomized, controlled trial. Stroke 2007;38:2518-2525.

4. Hofmeijer J, Kappelle LJ, Algra A, Amelink GJ, van Gijn J, van der Worp HB. Surgical decompression for space-occupying cerebral infarction (the hemicraniectomy after middle cerebral artery infarction with life-threatening edema trial [HAMLET]): A multicenter, open, randomised trial. Lancet Neurol 2009;8: 326-333.

5. Juttler E, Unterberg A, WoitzikJ, Bosel J, Amiri H, Sakowitz OW, et al. Hemicraniectomy in older patients with extensive middle cerebral artery stroke. NEngl J Med 2014;370:1091-1100.

6. Frank JI, Schumm LP, Wroblewski K, Chyatte D, Rosengart AJ, Kordeck C, et al. Hemicraniectomy and durotomy upon deterioration from infarction-related swelling trial: randomized pilot clinical trial. Stroke 2014;45:781-787.

7. Vahedi K, Hofmeijer J, Juettler E, Vicaut E, George B, Algra A, et al. Early decompressive surgery in malignant infarction of the middle cerebral artery: a pooled analysis of three randomised controlled trials. Lancet Neurol 2007;6:215-222.

8. Guidelines for management of ischaemic stroke and transient ischaemic attack 2008. Cerebrovasc Dis 2008;25:457-507.

9. Scottish Intercollegiate Guidelines Network: Management of patients with stroke or TIA: assessment, investigation, immediate management and secondary prevention. http://www.sign. ac.uk/pdf/sign108.pdf.

10. RCP. National clinical guideline for stroke. 3rd ed. http://bookshop.rcplondon.ac.uk/details.aspx? $\mathrm{e}=250$.

11. Jauch EC, Saver JL, Adams HP Jr, Bruno A, Connors JJ, Demaerschalk BM, et al. Guidelines for the early management of patients with acute ischemic stroke: a guideline for healthcare professionals from the American Heart Association/American Stroke Association. Stroke 2013;44:870-947

12. Wijdicks EF, Sheth KN, Carter BS, Greer DM, Kasner SE, Kimberly WT, et al. Recommendations for the management of cerebral and cerebellar infarction with swelling: a statement for healthcare professionals from the American Heart Association/ American Stroke Association. Stroke 2014;45:1222-1238.

13. Olsen TS, Langhorne P, Diener HC, Hennerici M, Ferro J, Sivenius J, et al. European stroke initiative recommendations for stroke management: update 2003. Cerebrovasc Dis 2003;16: 311-337.

14. Adams HP Jr, del Zoppo G, Alberts MJ, Bhatt DL, Brass L, Furlan A, et al. Guidelines for the early management of adults with ischemic stroke: a guideline from the American Heart Association/American Stroke Association stroke council, clinical cardiology council, cardiovascular radiology and intervention council, and the atherosclerotic peripheral vascular disease and quality of care outcomes in research interdisciplinary working groups: the American academy of neurology affirms the value of this guideline as an educational tool for neurologists. Stroke 2007;38:1655-1711.

15. Oppenheim C, Samson Y, Manai R, Lalam T, Vandamme X, Crozier $S$, et al. Prediction of malignant middle cerebral artery infarction by diffusion-weighted imaging. Stroke 2000;31: 2175-2181.

16. Wagner S, Schnippering H, Aschoff A, Koziol JA, Schwab S, Steiner T. Suboptimum hemicraniectomy as a cause of additional cerebral lesions in patients with malignant infarction of the middle cerebral artery. J Neurosurg 2001;94:693-696.

17. Chung JH, Bang OY, Lim YC, Park SK, Shin YS. Newly suggested surgical method of decompressive craniectomy for patients 
with middle cerebral artery infarction. Neurologist 2011;17: 11-15.

18. Park J, Kim E, Kim GJ, Hur YK, Guthikonda M. Exnternal decompressive craniectomy including resection of temporal muscle and fascia in malignant hemispheric infarction. J Neurosurg 2009;110:101-105.

19. Robertson SC, Lennarson P, Hasan DM, Traynelis VC. Clinical course and surgical management of massive cerebral infarction. Neurosurgery 2004;55:55-62.

20. Lee SC, Wang YC, Huang YC, Tu PH, Lee ST. Decompressive surgery for malignant middle cerebral artery syndrome. J Clin Neurosci 2013;20:49-52.

21. Iwama T, Yamada J, Imai S, Shinoda J, Funakoshi T, Sakai N. The use of frozen autogenous bone flaps in delayed cranioplasty revisited. Neurosurgery 2003;52:591-596.

22. Sobani ZA, Shamim MS, Zafar SN, Qadeer M, Bilal N, Murtaza SG. Cranioplasty after decompressive craniectomy: an institutional audit and analysis of factors related to complications. Surg Neurol Int 2011;2:123-128.

23. Gooch MR, Gin GE, Kenning TJ, German JW. Complications of cranioplasty following decompressive craniectomy: analysis of 62 cases. Neurosurg Focus 2009;26:E9.

24. Wachter D, Reineke K, Behm T, Rohde V. Cranioplasty after decompressive hemicraniectomy: underestimated surgery-as- sociated complications? Clin Neurol Neurosurg 2013;115: 1293-1297.

25. Yadla S, Campbell PG, Chitale R, Maltenfort MG, Jabbour P, Sharan AD. Effect of early surgery, material, and method of flap preservation on cranioplasty infections: a systematic review. Neurosurgery 2011;68:1124-1130.

26. Archavlis E, Carvi Y, Nievas M, Coppa ND, Delashaw JB. The impact of timing of cranioplasty in patients with large cranial defects after decompressive hemicraniectomy. Acta Neurochir (Wien) 2012;154:1055-1062.

27. Piedra MP, Ragel BT, Dogan A, Coppa ND, Delashaw JB. Timing of cranioplasty after decompressive craniectomy for ischemic or hemorrhagic stroke. J Neurosurg 2013;118:109-114.

28. Akins PT, Guppy KH. Sinking skin flaps, paradoxical herniation, and external brain tamponade: a review of decompressive craniectomy management. Neurocrit Care 2008;9:269-276.

29. Sarov M, Guichard JP, Chibarro S, Guettard E, Godin O, Yelnik A, et al.; DECIMAL investigators. Sinking skin flap syndrome and paradoxical herniation after hemicraniectomy for malignant hemispheric infarction. Stroke 2010;41:560-562.

30. Kim BJ, Hong KS, Park KJ, Park DH, Chung YG, Kang SH, et al. Customized cranioplasty implants using three-demensional printers and polymethyl-methacrylate casting. J Korean Neurosurg Soc 2012;52:541-546. 